\title{
Prevalence of active school transportation in the upper east and upper west regions of Ghana
}

\author{
Seidu Sofo', Eugene F. Asola ${ }^{2}$ and Emmanuel Thompson ${ }^{3}$ \\ ${ }^{1}$ Department of Health, Human Performance \& Recreation, Southeast Missouri State University, USA \\ ${ }^{2}$ Department of Kinesiology \& Physical Education, Valdosta State University, USA \\ ${ }^{3}$ Department of Mathematics, Southeast Missouri State University, USA
}

\section{Article Info}

Article history:

Received Nov 24, 2018

Revised Jan 30, 2019

Accepted Feb 14, 2019

\section{Keywords:}

Active transportation

Body mass index

Ghana

Physical activity

Students

\begin{abstract}
The use of active transportation such as walking to and from school is on the decline globally. The primary purpose of the study was to determine the prevalence of active school transportation among primary and junior high school students in the upper east and upper west regions of Ghana. The secondary purpose was to examine predictors for meeting the recommended daily number of steps. A total of 2,505 (1,117 boys and 1,388 girls) primary $(1,583)$ and junior high school (922) students participated in the study. The distances from children's homes to their schools, heights, and body weights were measured -their heights were used to estimate their stride lengths. The step count for each participant to and from school each day was calculated. Data were analyzed using conditional percentage distribution and Logit model. Analyses indicated that $98.96 \%$ of participants used active transportation to and from school. Over $63 \%$ of the students were within the normal BMI range. However, $26.47 \%$ of the participants were either thin or underweight while $9.9 \%$ were either overweight or obese. Overall, $46.47 \%$ of the participants met the recommended daily steps. The Logit model indicated that education level, BMI, mode of transportation, region, height, and age were significant predictors for meeting the recommended daily number of steps. The prevalence of school active transportation in the present study was high compared to that reported in other studies. Furthermore, the prevalence of thinness and underweight were higher than in previous studies, while the prevalence in overweight and obesity were lower.
\end{abstract}

Copyright (C) 2019 Institute of Advanced Engineering and Science. All rights reserved.

\section{Corresponding Author:}

Emmanuel Thompson,

Department of Mathemtics,

Southeast Missouri State University,

1 University Plaza, Cape Girardeau, MO 63701, USA.

Email: ethompson@semo.edu

\section{INTRODUCTION}

The World Health Organization (WHO) classifies physical inactivity as the fourth leading cause of global mortality, and a major determinant for various chronic diseases [1]. Globally, there has been a behavioral shift from traditionally active lifestyles, to more industrialized and sedentary lifestyles [2]. This decline in physical activity levels, coupled with increasing sedentary behaviors is referred to as "physical activity transition" [2]. Sedentary lifestyles are major causes of chronic non-communicable diseases such as obesity, coronary diseases, and diabetes [3]. Furthermore, diseases such as childhood obesity should be a major public health concern, since obese children would likely be obese as adults [4].

Many adolescents do not accrue the recommended daily physical activity levels [5]. Small frequent amounts of physical activity such as walking, or cycling can result in positive health outcomes [6]. 
Children and adolescents who use active transportation are more likely to be moderately active than those who do not [7]. Unfortunately, research shows a global decline in the use of active transportation, such as walking to school [8]. Active transportation to and from school can contribute to the overall wellbeing of children and adolescents, as active commuting is shown to be positively related to health-related physical fitness components [9].

Sub-Saharan African economies that are based on manual labor are rapidly being replaced by industries and mechanization [10]. These, coupled with urbanization and the appetite for white collar jobs, has resulted in a shift from high-energy expenditure physical activities such as active transportation and manual labor to low-energy expenditure physical activities such as motorized transport and desk work [1]. This trend has resulted in what is termed "steps in reserve" which are the steps that individuals could take but do not because they choose to use motorized modes of transport [11]. Evidence shows key findings for physical activity among children and youth in Sub-Saharan Africa. First, lower socioeconomic status and rural children have higher levels of physical activity than higher socioeconomic status and urban children. Second, boys have higher levels of physical activity than girls [12]. Third, there are relatively low rates of active transportation to and from school [13-15].

Data on the physical activity levels of children and youth in Ghana are scarce. The results of Ghana's 2014 and 2016 report cards on physical activity for children and youth were efforts to address the scarcity of data [16-17]. The report cards showed that Ghana received grades of "D" and "C " in the active transportation category in 2014 and 2016 respectively. However, the 2014 finding was based on a study of urban high school students [18]. The 2016 report card indicated that approximately $74 \%$ of students walked to school while $7 \%$ commuted by bicycle [17]. To ensure school-aged adolescents achieve fitness standards, the Ministry of Health recommended the addition of 120 minutes of compulsory physical education in the school curriculum [19].

To date, very few studies have investigated the interactions of active school transportation and demographic characteristics of children and adolescents in Ghana. Therefore, the primary purpose of the study was to determine the prevalence of active school transportation among primary and junior high school students in the Upper East and Upper West regions of Ghana. The secondary purpose was to examine predictors for meeting the recommended daily number of steps. The identification of the prevalence and predictors of active school transportation and physical activity would allow policy makers and health and educational administrators to better understand and develop national strategies for increasing active lifestyles among school-aged children and the adolescents.

\section{METHOD}

\subsection{Participants and settings}

Participants for the study included a purposive sample of 2,505 (1,117 boys and 1,388 girls) primary (PRIM) and junior high school (JHS) students from one municipality and one district in the upper east and upper west regions of Ghana respectively. The sample consisted of 1583 and 922 children and adolescents from primary and junior high schools respectively. Their ages ranged from 5.25 to 24.42 years $(\mathrm{M}=12.68, \mathrm{SD}=3.35$, Skewness=.05). Primary (PRIM) and junior high schools (JHS) are part of Basic Education in Ghana which includes Kindergarten lasting two years (Age 4-6), PRIM lasting six years (Age 6-11), and JHS lasting three years (Age 12-15). Thus, the official age range for students from PRIM to JHS is 6-15 years. However, the ages for participants in the present study ranged from 5.25 to 24.42 years. High rates of poverty in the two regions often result in late entry and temporary school dropouts which, in turn, contribute to overage school attendance.

The Upper East and Upper West Regions of Ghana lie in the northern most part of the country, with projected populations of 1.2 million and 830,000 respectively. The Upper East Region, with Bolgatanga as the regional capital, is bordered by Burkina Faso to the north, Togo to the east, and the Upper West and Northern Regions to the west and south respectively. The Upper West Region, with Wa as its regional capital, is bordered by Burkina Faso to the north, Ivory Coast to the west, and the Upper East and Northern regions to the east and south respectively. Both regions are predominantly rural, with low school enrollments and literacy rates compared to the rest of the country (except the Northern Region). The streets and roads in the towns and villages in both regions lack sidewalks, footpaths or open spaces. In addition, it is not uncommon for unauthorized structures to be erected along streets or in officially designated open spaces, resulting in poor walkability. The Human Subjects Committee at the first author's institution granted approval for the study. The District and Municipal Directorates of Education granted permission to conduct the study in their respective schools. Parental written consents were obtained prior to data collection. Students who verbally agreed to take part in the study were notified that participation was voluntary, and that they could withdraw at any time.

Prevalence of active school transportation in the upper east and upper west regions of Ghana (Seidu Sofo) 


\subsection{Measures}

\subsubsection{Questionnaire}

A questionnaire was used to collect the following demographic information for the study: age, child's sex, grade level, and region. In addition, the questionnaire gathered data on students' home location and mode of transport to and from school. The questionnaires were completed by the classroom teachers. The students self-reported their places of residence (home) and the mode of transport to and from school - the teachers entered these on the questionnaires. Teachers extracted each participant's sex and age from class rosters. Using a zoning method, the researchers estimated the distance between each participant's home and the school. The distance traveled to and from school each day was determined by multiplying the distance from school by two. Students' names or any identifiable information were not indicated on the completed questionnaires. The teachers assigned students identification numbers on the questionnaire with their corresponding information. The teachers in the Upper West and Upper East regions handed the completed questionnaires in sealed envelopes to the first and second authors respectively.

To calculate the daily number of steps, the stride length for each participant was estimated by multiplying height $(\mathrm{cm})$ by 0.415 for boys and 0.413 for [20]. To calculate the daily number of steps, the distance traveled to and from school each day was divided by the stride length. In addition, children who rode bicycles to and from school reported the time it took them to travel to school. This allowed the researchers to calculate how fast they traveled (kilometer per minute) [21]. The number of steps for each cyclist was estimated using the activity conversion chart from [22].

\subsubsection{Body Mass Index (BMI)}

BMI was calculated from height and weight. Participants' heights were measured by the researchers to the nearest 0.1 centimeter $(\mathrm{cm})$, using wall mounted wooden tapes [9]. Participants stood erect on a flat surface without shoes on and with their backs against the wall with feet parallel and hands hanging on the sides. Height measured in centimeters was converted to meters for computing BMI. The researchers measured body weight with a Tefal Glass Classic (Model P1101V) Bathroom Scale to the nearest 0.1 kilogram $(\mathrm{kg})$. Children stood on the scale in light clothes and without shoes on, and with their arms by the sides. BMI was calculated by dividing the person's weight $(\mathrm{kg})$ by the height $(\mathrm{m})$ squared $\left(\mathrm{kg} / \mathrm{m}^{2}\right)$. For ages 5-19 years, BMI-for-age cut-offs [23] were used to classify BMI. The values <-2 SD, <1 SD, median, $>+1 \mathrm{SD}$, and $>+2 \mathrm{SD}$ were classified as thinness, underweight, normal range, overweight, and obese respectively. For participants 20 years and above, BMI values of <16.00, <18.5, 18.5-24.9, >25.00, and $>30.00$ were classified as thinness, underweight, normal range, overweight, and obese respectively [23].

\subsection{Variables}

The response variable for the study was the recommended daily number of steps $(10,000$ steps $)$. Nine (9) predictors were used (refer to Appendix A): Child's sex, educational level, BMI, mode of transport, region, active transport, body weight, height, and age. Before fitting the logit model, the dataset was divided into two sets: Training and testing. The training set which constituted $70 \%$ of the entire dataset was used to specify the predictive model and the remaining $30 \%$ was used as a testing set to perform out-of-sample validation of the predictive accuracy of the model.

\subsubsection{Logit model}

Let $Y_{i}$ represent random variables taking values $y_{i} \in(0,1)$ with probability $1-\pi_{i}$ and $\pi_{i}$ respectively. This implies:

$$
f_{\pi_{i}}\left(y_{i}\right)=\pi_{i}^{y_{i}}\left(1-\pi_{i}^{y_{i}}\right)
$$

Suppose the logit of probability of $\pi_{i}$ is given by:

$$
\log \left(\frac{\pi_{i}}{1-\pi_{i}}\right)=X_{i}^{T} \beta \Rightarrow \pi_{i}=\frac{e^{X_{i}^{T} \beta}}{1+e^{X_{i}^{T} \beta}}
$$

The predictive form of (2) can be written as:

$$
\pi\left(\beta \mid X_{i}\right)=\frac{1}{1+e^{-X_{i}^{T} \beta}}
$$

Where $X_{i}$ and $\beta$ are vectors of predictors and slopes respectively. To estimate (2), the loglikelihood is given by: 
$l(\beta)=\log \left[\prod_{i=1}^{n} f_{\pi_{i}}\left(y_{i}\right)\right]$,

$=\sum_{i=1}^{n}\left[y_{i} \log \left(\pi_{i}\right)+\left(1-y_{i}\right) \log \left(1-\pi_{i}\right)\right]$,

$=\sum_{i=1}^{n}\left[y_{i} \log \left(\pi\left(\beta \mid X_{i}\right)\right)+\left(1-y_{i}\right) \log \left(1-\pi\left(\beta \mid X_{i}\right)\right)\right]$.

Let $\nabla l(\beta)=\frac{\partial l(\beta)}{\partial \beta_{k}}$ and $H(\beta)=\frac{\partial^{2} l(\beta)}{\partial \beta_{k} \partial \beta_{m}}$ represent the gradient of the loglikelihood and the hessian matrix respectively. No closed-form solution, so resort to Newton Raphson's algorithm for approximate solution. Newton Raphson's algorithm [24] is given as follows:

a. Start from some initial values $\beta_{0}$.

b. Set $\beta_{k}=\beta_{k-1} H\left(\beta_{k-1}\right)^{-1} \nabla l\left(\beta_{k-1}\right)$ (a loop).

c. Repeat step 2 until $\beta_{k}$ is close to $\beta_{k-1}$.

Inference is carried out as follows:

$$
\sqrt{n}(\hat{\beta}-\beta) \rightarrow N\left(0, I(\beta)^{-1}\right) \text { as } n \rightarrow \infty,
$$

where $I(\beta)=-H(\beta)$ is fisher information and $I(\beta)^{-1}$ is the variance-covariance matrix.

\subsubsection{Prediction metrics}

A confusion matrix contains information about actual and predicted classifications done by a classification system. Table 1 shows the confusion matrix for a two-class classifier. The true positive rate (TPR) is given by the ratio of the true positive (TP) to the sum of the true positive and false negative (FN). The false positive rate (FPR) is obtained as the ratio of the false positive (FP) to the sum of the false positive and true negative $(\mathrm{TN})$.

Table 1. Confusion matrix

\begin{tabular}{|c|c|c|c|c|c|}
\hline & \multicolumn{3}{|c|}{ Predicted Class } & \multirow[t]{2}{*}{ Total } & \multirow[t]{2}{*}{ Rate } \\
\hline & & $\hat{Y}=1$ & $\hat{Y}=0$ & & \\
\hline \multirow{2}{*}{$\begin{array}{l}\text { Actual } \\
\text { Class }\end{array}$} & $Y=1$ & $T P$ & $F N$ & $T P+F N$ & $T P R=\frac{T P}{T P+F N}$ \\
\hline & $Y=0$ & $F P$ & $T N$ & $F P+T N$ & $F P R=\frac{F P}{F P+T N}$ \\
\hline
\end{tabular}

At different thresholds say $0.00,0.01, \ldots, 1.00$, a graph of TPR (sensitivity) against FPR (1- specificity) is plotted to obtain the receiver operating characteristic (ROC) curve. Numerically, the area under the ROC curve also referred to as the area under curve (AUC). The AUC measures the prediction accuracy of the logit model.

\subsection{Data analysis}

The authors used two-way tables to show the frequencies and percentages by which participants met or did not meet the recommended daily number of steps and the predictor variables. In addition, the conditional percentage distribution of each categorical predictor variable [25] was calculated for each level of the response variable. Initial data included 2,590 participants, but observations for $85(3.28 \%)$ were deleted due to missing data. All data were analyzed using the R-Studio software (Version 1.1.453-2009-2018 RStudio, Inc.).

\section{RESULTS AND DISCUSSION}

\subsection{Active transportation and meeting the recommended daily number of steps}

Table 2 presents data on the conditional percentage distribution of categorical predictors and recommended daily steps. The results showed that $98.96 \%$ of the participants used active transportation to and from school. Alternatively, only $1.04 \%$ of the participants used non-active transportation to and from school. Of those who used active transportation, $46.11 \%$ met the recommended daily number of steps while $53.89 \%$ did not. Most of the participants 2,221(88.66\%) walked to and from school while $260(10.38 \%)$ rode bikes, and the rest used other modes of transportation.

BMI analyses placed participants into five BMI categories as seen in Table 2: Thinness (11.86\%), Underweight $(14.61 \%)$, Normal (63.63\%), Overweight $(8.38 \%)$, and Obese $(1.52 \%)$. That is, $26.47 \%$ of the

\footnotetext{
Prevalence of active school transportation in the upper east and upper west regions of Ghana (Seidu Sofo)
} 
participants were either thin or underweight while $9.9 \%$ were either overweight or obese. Those in the "Thinness" category $(58.59 \%)$ had the highest percentage of participants meeting the daily recommended steps (10,000 steps), followed by the "Obese" and "Normal" categories with $52.63 \%$ and $44.86 \%$ respectively.

Data in Table 2 indicates that $46.11 \%$ of students who used active transportation (walking and biking) met the daily recommended steps. Alternatively, of their counterparts who traveled to and from school by car/bus (70.00\%) and 'Other" (Motor cycles) $(85.71 \%)$ motorized means of transport accrued "steps in reserve" that would have met the recommended daily number of steps [11]. Children who went to school by car or motorcycle were sent by their parents or other adult family members. The buses were usually part of public transportation.

Table 2. Conditional percentage distribution of categorical predictors and recommended daily steps

\begin{tabular}{ccc}
\hline Variable & Met & Not Met \\
\hline Active Transportation & Frequency(Percentage) & Frequency(Percentage) \\
Non-Active & $21(80.77)^{*}$ & $5(19.23)^{*}$ \\
Active & $1143(46.11)$ & $1336(53.89)$ \\
Mode of Transportation & & \\
Walking & $947(42.64)$ & $1274(57.36)$ \\
Biking & $198(76.15)$ & $62(23.85)$ \\
Car/Bus & $7(70.00)^{*}$ & $3(30.00)^{*}$ \\
Other (Motor cycle) & $12(85.71)^{*}$ & $2(14.29)^{*}$ \\
Educational Level & & \\
JHS & $240(26.03)$ & $682(73.97)$ \\
PRIM & $924(58.37)$ & $659(41.63)$ \\
Child's Sex & & \\
Female & $613(44.16)$ & $775(55.84)$ \\
Male & $551(49.33)$ & $566(50.67)$ \\
BMI & & \\
Thinness & $174(58.59)$ & $123(41.41)$ \\
Underweight & $161(43.99)$ & $205(56.01)$ \\
Normal & $715(44.86)$ & $879(55.14)$ \\
Overweight & $94(44.76)$ & $116(55.24)$ \\
Obese & $20(52.63)$ & $18(47.37)$ \\
Region & & \\
UER & $307(33.48)$ & $610(66.52)$ \\
UWR & $857(53.97)$ & $731(46.03)$ \\
\hline USteps in reserve & &
\end{tabular}

Table 3 shows data on the conditional mean and standard deviation distribution of continuous predictors and recommended daily steps. Table 3 indicates that 1,164 (46.47\%) of the participants met the recommended daily number of steps. The data show that participants who met the recommended daily number of steps had lower mean scores in age, weight, height, and BMI than those who did not accrue the recommended daily number of steps.

Table 3. Conditional mean and standard deviation distribution of continuous predictors and recommended daily steps

\begin{tabular}{|c|c|c|c|c|c|c|}
\hline \multirow[t]{2}{*}{ Variable } & \multicolumn{3}{|c|}{ Met $(\mathrm{N}=1.164)$} & \multicolumn{3}{|c|}{ Not Met $(\mathrm{N}=1.341)$} \\
\hline & Mean(Standard Error) & Min & Max & Mean(Standard Error) & Min & Max \\
\hline Age (Months) & $136.8(1.08)$ & 63 & 240 & $165.4(1.04)$ & 68 & 293 \\
\hline Weight (kg) & $34.59(0.36)$ & 16.5 & 85 & $43.48(0.35)$ & 18 & 82 \\
\hline Height $(\mathrm{cm})$ & $141.19(0.44)$ & 99.06 & 194 & $151.7(0.44)$ & 100 & 188 \\
\hline BMI & $16.97(0.11)$ & 8.77 & 57.07 & $18.49(0.08)$ & 9.82 & 34.68 \\
\hline Distance to and from School $(\mathrm{km})$ & $8.35(0.08)$ & 5.2 & 30 & $3.63(0.06)$ & 0.2 & 7 \\
\hline Daily Number of steps & $14352.19(126.09)$ & 10008 & 49081 & $5718.01(88.44)$ & 352 & 9989 \\
\hline
\end{tabular}

\subsection{Predictors of students meeting the recommended daily steps}

Table 4 presents data on the estimated z-score, odds ratio and the corresponding probability for the reduced logit model. Six of the predictor variables significantly predicted students' ability to meet the recommended daily steps. The variables were educational level, BMI, mode of transportation, region, height, 
and age. Alternatively, weight was not significant. Junior High (JHS) students had lower odds than their primary school (PRIM) counterparts to meet the recommended daily steps. The "Normal" category served as the reference group for the variable BMI. Students in the "Thinness" and "Underweight" categories had higher odds of meeting the recommended steps than those in the "Normal" category. Conversely, participants in the "Overweight" and "Obese" categories had lower odds of meeting the recommended daily steps than those in the "Normal" category, but these were not significant.

Students in the "walking" category served as the reference group for mode of transportation. Those in the "biking" category had higher odds of meeting the recommended daily number of steps than those who walked to and from school. Students in the Upper West Region had higher odds of meeting the recommended steps than those in the Upper East Region. Furthermore, the odds of meeting the recommended daily steps decreased with an increase in height. Finally, an increase in age resulted in a decrease in the odds of meeting the daily recommended number of steps.

Table 4. Estimated Z-score, odds ratio and the corresponding probability for the reduced logistic model

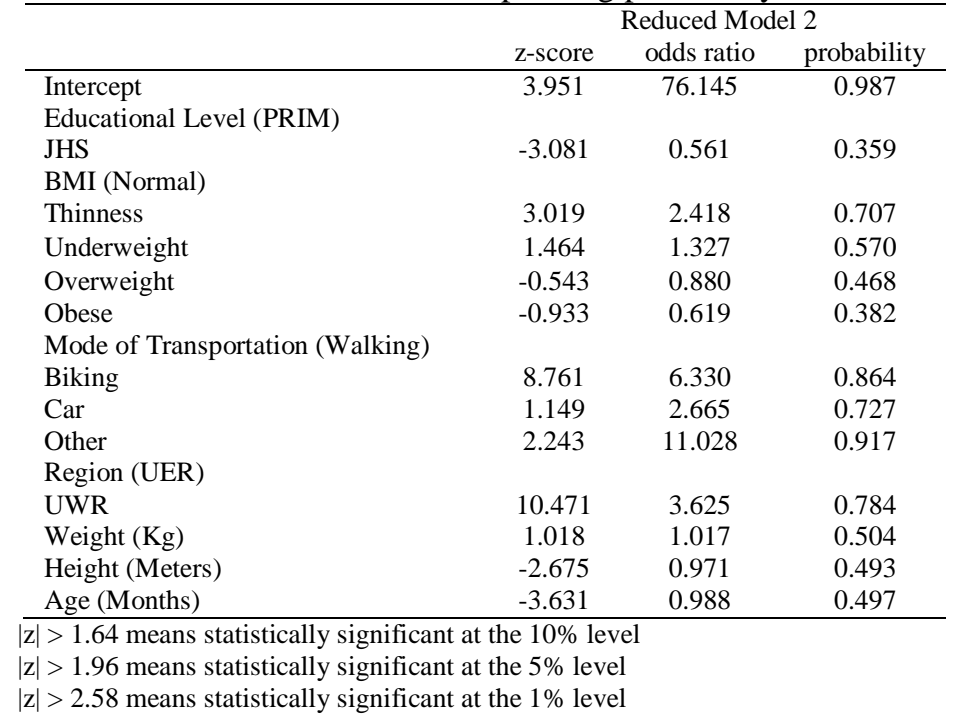

\subsection{Summary results}

The present study examined the prevalence and predictors of active school transportation among primary and junior high school students in the Upper East and Upper West regions of Ghana. The study identified five main findings. First, most participants used active transport to and from school. Second, over $63 \%$ of the children and adolescents were in the normal BMI range, while $26.47 \%$ were either thin or underweight and $9.9 \%$ were either overweight or obese. Third, $46.47 \%$ of the participants met the daily recommended 10,000 steps. Fourth, participants who met the recommended daily number of steps had lower mean scores in age, weight, height, and BMI than those who did not accrue the recommended number of steps. Finally, educational level (PRIM or JHS), BMI, mode of transportation, region, height, and age were significant predictors for meeting recommended daily number of steps.

The present study examined the prevalence of active school transportation and predictors of physical activity among primary and junior high school students in the Upper East and Upper West regions of Ghana. The first major finding was that over $98 \%$ of the students in the study used active transportation to and from school. This contradicts the declining global trend [8] and specifically Ghana [16-17]. The prevalence of active transportation in the present study was higher than the $81 \%-87 \%$ prevalence reported for the Upper East and Upper West regions by [17].

Second, the prevalence of obesity in the present study was lower than the $17 \%$. Conversely, children and adolescents in the current study had a higher prevalence of thin or underweight than the national average of $13 \%$ reported by [27] and $16.7 \%$ and $6.7 \%$ stunting and thinness respectively by [28]. The "double burden" of malnutrition, the concurrent existence of under and over nutrition [29], has serious consequences for the development of low-and middle-income countries. Undernutrition can negatively impact children's development and learning. Even though children may catch up from stunting [30], they may not recover from the cognitive delay associated with [31].

Third, participants in primary schools were more likely than those in junior high schools to meet the recommended daily number of steps. Similarly, older students had lower odds of meeting the recommended

Prevalence of active school transportation in the upper east and upper west regions of Ghana (Seidu Sofo) 
steps. This finding is supported by the assertion that continuous participation in physical activity by schoolaged children and adolescents increases the probability of being active during adulthood [32]. Fourth, participants who met the recommended daily steps had a lower mean BMI score that those who did not. This finding is consistent with that of [33], which indicated that participants with low levels of physical activity had significantly high prevalence of overweight and central obesity than those who had high levels of physical activity. Analyzing data from the Ghana Global School-Based Student Health Survey [34-35] reported a significant negative association between BMI and physical activity and participation in physical education classes among junior high and senior high students. That is, students who were overweight or obese were less likely to participate in physical activities or in physical education classes. Fifth, students in the UWR school district had higher odds than their counterparts in urban schools in the UER to meet the recommended daily number of steps. This finding is consistent with that of [36] which indicated that active transportation was lower among urban populations than rural groups in Ghana.

The study had three main strengths. First, the study investigated active transportation simultaneously with multiple variables such as demographic information, anthropometric measures, and distance from school. Previous studies have focused on active transportation and demographic information. A second strength of the study was allowing teachers to complete the questionnaire. Teachers had access to records on students' age, and grade levels. In addition, it addressed the inadequacies in children's reading abilities, especially at the PRIM level. Finally, the study utilized a rigorous statistical tool to tease out the important predictors of participants' ability to meet the recommended daily number of steps.

Despite the strengths of the study, two limitations are worth noting. First, student bicycle riders' self-report on how long it took them to travel to school was a major limitation. The use of a more objective measure of their stride length would be more appropriate. Second, the sample in the study was not representative of primary and junior high school students in the two regions. A random selection of schools would have produced a sample that would reflect the prevalence of active school transportation in the two regions. Furthermore, the present study utilized a small sample size, a larger sample of multiple school districts/municipalities would result in more representative outcomes.

\section{CONCLUSION}

The present study reported a very high prevalence of active school transportation-most children walked to and from school. Also, it identified child's educational level, BMI, mode of transportation, region (rural or urban), height, and age as significant predictors for meeting recommended daily number of steps. The prevalence of school active transportation in the present study was high compared to that reported in other studies on Ghanaian children and adolescents. In addition, prevalence of thinness and underweight were found to be higher than in previous studies. However, prevalence in overweight and obesity were low compared to those found in other studies on Ghana.

\section{IMPLICATIONS FOR SCHOOL HEALTH AND PHYSICAL ACTIVITY}

The findings from the present study have implications for school health and physical education. First, there is the need to identify strategies to increase physical activity through before and/or after school programs and school physical education. Before and/or after school programs such as walking/running clubs would provide students with additional opportunities to accrue the recommended physical activity levels. Such clubs could be integral parts of the School Health Program. Second, primary school students were more active and more likely to meet the daily physical activity requirements compared to junior high school students. It is therefore pertinent to implement interventions at the junior high school level to sustain levels of physical activity accrued in the primary school. This would increase students' likelihood of being active later in adulthood. Third, school feeding programs could help reduce the "double burden" of malnutrition [29] in Ghanaian schools, as they have the potential to positively effect stunting and overweight simultaneously [37]. In addition to providing students' daily nutritional requirements, school feeding programs could serve as avenues for educating students about healthy dietary habits. Finally, students who rode bicycles were more likely than those who walked to and from school of meeting the recommended daily number of steps. This necessitates the provision of bicycle accessible roads in cities and towns. Furthermore, the present study showed that students in the urban schools were less likely than their colleagues in less urban areas to meet the recommended activity levels. Thus, the availability of bicycle lanes in the cities are particularly critical for students' physical activity behaviors and overall health. 


\section{FUTURE RESEARCH}

Future research should replicate the present study in other regions of the country. Also, nation-wide studies using multistage sampling to select a representative sample are needed. Second, future research should use objective measures for assessing school active transportation. The present study utilized self-report questions to estimate the distances from students' homes to their schools. For example, an objective measure such as the Global Positioning Systems (GPS) technology could be used to determine students' distances from students' homes to the schools. Furthermore, objective measures such as pedometers could be used to estimate the number of steps students accrue daily to and from school. Third, future research should investigate the relationship between availability of the School Feeding Program and the level of physical activity among students

\section{ACKNOWLEDGEMENTS}

The authors would like to thank the students for their participation and the teachers for their assistance in completing the questionnaires and for organizing the students for the anthropometric measures.

\section{REFERENCES}

[1] World Health Organization; "Global health risks: Mortality and burden of disease attributable to selected major risks," 2009. WHO: Geneva, Switzerland.

[2] Katzmarzyk, P.T; Mason, C.; "The physical activity transition," Journal of Physical Activity and Health, vol. 6, no. 3, pp. 269-280, 2009. DOI: https://doi.org/10.1123/jpah.6.3.269.1

[3] Martyniuk, O.J.; Tucker, P.; 'An exploration of early childhood education students' knowledge and preparation to facilitate physical activity for preschoolers: A cross-sectional study,” BMC Public Health, vo. 14, p. 727, 2014. DOI: $10.1186 / 1471-2458-14-727$.

[4] Serdula, M.K.; Ivery, D.; Coates, R.J., Freedman, D.S.; Williamson, D.F.; Byers, T.; "Do obese children become obese adults? A review of the literature," Preventive Medicine, vol. 22, no. 2, pp. 167-177, 1993.

[5] Mummer, K.W.; Spence, J.C.; Hudec, J.C.; "Understanding physical activity intention in Canadian school children and youth: An application of the theory of planned behavior," Research Quarterly for Exercise and Sport, vol. 71, no. 2, pp. 116-124, 2000. DOI: 10.1080/02701367.2000.10608889.

[6] Boreham, C.A.; Wallace, W.F.; Nevill, A.; "Training effects of accumulated daily stair-climbing exercise in previously sedentary young women," Preventive Medicine, vol. 30, no. 4, pp. 277-281. 2000. DOI: $10.1006 /$ pmed.2000.0634.

[7] Schofield, G.; Schofield, L.; Mummery, K.; "Active transportation: An important part of adolescent physical activity," Youth Studies Australia, vol. 24, no. 1, pp. 43-47, 2005.

[8] Buliung, R.; Faulkner, G.; Beesley, T.; Kennedy, J.; "School travel planning: Mobilizing school and community resources to encourage active school transportation," Journal of School Health, vol. 81, no. 11, pp. 704-712

[9] Østergaard, L.; Kolle, E.; Steene-Johannessen, J.; Anderssen, S.A.; Andersen, L.B.; "Cross sectional analysis of the association between mode of school transportation and physical fitness in children and adolescents," International Journal of Behavioral Nutrition and Physical Activity, vol. 10, no. 91, 2013. DOI: 10.1186/1479-5868-10-91.

[10] Popkin, B.M.; Gordon-Larsen, P.; "The nutrition transition: Worldwide obesity dynamics and their determinants," International Journal of Obesity, vol. 28, pp. S2-S9, 2004.

[11] Morency, C.; Roorda, M.J.; Demers, M.; "Comparing latent walk trips in Toronto, Ontario, and Montreal, Quebec, Canada," Transportation Research Record, vol. 21, no. 1, pp. 111-119, 2009. Doi: https://doi.org/10.3141/2140-12.

[12] Muthuri, S.K.; Wachira, L.J.M.; Leblanc, A.G.; Francis, C.E.; Sampson, M.; Onywera, V.O. et al.; “Temporal Trends and Correlates of Physical Activity, Sedentary behaviour, and physical fitness among school-aged children in Sub-Saharan Africa: A Systematic Review," International Journal of Environmental Research and Public Health, 11(3), pp. 3327-3359, 2014. DOI:10.3390/ijerph110303327.

[13] Guthold, R., Cowan, M.J., Autenrieth, C.S., Kann, L., Riley, M., Physical activity and sedentary behavior among schoolchildren: a 34-country comparison. Journal of Pediatrics, vol. 157, no. 1, pp. 43-49, 2010. DOI: https://doi.org/10.1016/j.jpeds.2010.01.019.

[14] Onywera, V.O.; Adamo, K.B.; Sheel, A.W.; Waudo, J.N.; Boit, M.K.; Tremblay, M.; "Emerging evidence of the physical activity transition in Kenya," Journal of Physical Activity and Health, vol. 9, no. 4, pp. 554-562, 2012.

[15] Peltzer, K.; "Health behavior and protective factors among school children in four African countries," International Journal of Behavioral Medicine, vol. 16, no. 2, pp. 172-180, 2009.

[16] Ocansey, R.; Aryeetey, R.; Sofo, S.; Delali, M.; Pambo, P.; Nyawornota, V.K.; "Results from Ghana's 2014 report card on physical activity for children and youth," Journal of Physical Activity and Health, vol. 11, (S1): pp. S58S62. 2014. DOI: https://doi.org/10.1123/jpah.2014-0171. 
[17] Ocansey, R.; Aryeetey, R., Sofo, S.; Nazzar, A.; Delali, M.; Pambo, P.; et al.; "Results from Ghana's 2016 report card on physical activity for children and youth," Journal of Physical Activity and Health, vo. 13, no. 11, Supplement 2, pp. S165-S168, 2016. DOI: https://doi.org/10.1123/jpah.2016-0272.

[18] Aryeetey, R.; "Environmental barriers to outdoor physical activity in East Legon: A qualitative street audit," Ghana Physical Education and Sport Journal, vol. 2, no. 2, pp. 42-50, 2011.

[19] Ministry of Health; "Dietary and physical activity guidelines for Ghana," 2009. MOH: Accra.

[20] Soleus; "Determining your stride length," n.d. Retrieved November 1, 2017 from https://cdn.shopify.com/s/files/1/0196/4616/files/Soleus-determing_your_stride.pdf.

[21] Gropp, K.; Janssen, I.; Pickett, W., "Active transportation to school in Canadian youth: Should injury be a concern?” Injury Prevention, vol. 19, no. 1, pp. 64-67, 2013. DOI: 10.1136/injuryprev-2012-040335.

[22] Washington University in St. Louis; "MyHealth: Activity conversion chart," n.d. Retrieved from https://mywaytohealth.wustl.edu/wp-content/uploads/2015/09/Activity-Conversion-Chart.pdf.

[23] World Health Organization; "BMI-for-age: 5-19 years," classification," 2007. Retrieved December 15, 2017 from http://www.who.int/growthref/who2007_bmi_for_age/en/.

[24] Charpentier, A.; "Computational actuarial science in R," 2015. Boca Raton, FL: Taylor and Francis Group.

[25] Utts, J.M.; "Seeing through statistics (4th Ed.)" 2015. Stamford, CT: Cengage learning.

[26] Aryeetey, R.; Lartey, A.; Marquis, G.S; Nti, H.; Colecraft E.; Brown P.; "Prevalence and predictors of overweight and obesity among school-aged children in urban Ghana," BMC Obesity, vol. 4, no. 38, pp. 1-8, 2017. DOI: 10.1186/s40608-017-0174-0.

[27] Ghana Statistical Service; "Ghana multiple indicator cluster survey with an enhanced malaria module and biomarker, (Final Report),” 2011. Ghana Statistical Service, Accra, Ghana.

[28] Kwabla, M.P.; Gyan, C.; Zotor, F.; "Nutritional status of in-school children and its associated factors in Denkyembour District, Eastern Region, Ghana: Comparing schools with feeding and non-school feeding policies," Nutrition Journal, vol. 17, no. 8, pp. 1-8, 2018. DOI: 10.1186/s12937-018-0321-6.

[29] Haddad, L.; Cameron, L.; Barnett, I.; "The double burden of malnutrition in SE Asia and the Pacific: priorities, policies and politics," Health Policy Plan, vol. 30, no. 9, pp. 1193-1206, 2015. DOI: https://doi.org/10.1093/heapol/czu110.

[30] Prentice, A.; Ward, K.; Goldberg, G.; Jarjou, L.M.; Moore, S.E.; Fulford, A.J.; et al.; "Critical windows for nutritional interventions against stunting," American Journal of Clinical Nutrition, vol. 97, no. 5, 2013. pp. 911918. DOI: https://doi. org/10.3945/ajcn.112.052332.

[31] Casale, D.; Desmond, C.; "Recovery from stunting and cognitive outcomes in young children: Evidence from the South African Birth to Twenty Cohort Study," Journal of Developmental Origins of Health and Disease, vol.7, no. 2, pp. 163-171, 2016. DOI: https://doi.org/10.1017/ S2040174415007175 21.

[32] Telama, R.; Yang, X.; Viikari, J.; Valimaki I.; Wanne O.; Raitakari O.; "Physical activity from childhood to adulthood: A 21-year tracking study," American Journal of Preventive Medicine, vol. 28, no. 3, pp. 267-273, 2005. DOI: https://doi.org/10.1016/j.amepre.2004.12.003.

[33] Mogre, V.; Mwinlenaa, P.P.; "Impact of physical activity levels and diet on central obesity among civil servants in Tamale metropolis," Journal of Medical and Biomedical Sciences, vol. 1, no. 2, pp. 1-9, 2012.

[34] World Health Organization; "Global school-based student health survey (GSHS): 2012 Ghana GSHS Quesitonnaire," 2012. Retrieved on August $1, \quad 2018$ from http://www.who.int/chp/gshs/GSHS_Core_Modules_2009_English.pdf.

[35] Sofo, S.; Thompson, E.; "Effects of body mass index and drunkenness on physical activity levels of adolescents in Ghana," International Journal of Health Research and Innovation, vol. 4, no. 2, pp. 45-54, 2016.

[36] Oyebode, O.; Pape, U.J.; Laverty, A.A.; Lee, J.T.; Bhan, N.; Millett, C.; "Rural, urban and migrant differences in non-communicable disease risk-factors in middle income countries: A cross-sectional study of WHO-SAGE data," PLOS ONE, vol. 10 no. 4, 2015. DOI: https://doi.org/10.1371/journal.pone.0122747.

[37] Graham, L.; Hochfeld, T.; Stuart, L.; "Double trouble: Addressing stunting and obesity via school nutrition," South African Journal of Child Health, vol. 12, no. 3, pp. 90-94, 2018. DOI:10.7196/SAJCH.2018.v12i3.1455. 